\title{
A Complementary Biodiesel Blend from Soapnut Oil and Free Fatty Acids
}

\author{
Yi-Hung Chen ${ }^{1, *}$, Ting-Cheng Tang ${ }^{1}$, Tsung-Han Chiang ${ }^{1}$, Bo-Yu Huang ${ }^{1}$, \\ Ching-Yuan Chang ${ }^{2}$, Pen-Chi Chiang ${ }^{2}$, Je-Lueng Shie ${ }^{3}$, Matthias Franzreb ${ }^{4}$ and \\ Lu-Yen Chen ${ }^{5}$
}

1 Department of Chemical Engineering and Biotechnology, National Taipei University of Technology, Taipei 106, Taiwan; E-Mails: t7830312@ntut.edu.tw (T.-C.T.); t8738027@ntut.edu.tw (T.-H.C.); s6902136@hotmail.com (B.-Y.H.)

2 Graduate Institute of Environmental Engineering, National Taiwan University, Taipei 106, Taiwan; E-Mails: cychang3@ntu.edu.tw (C.-Y.C.); pcchiang@ntu.edu.tw (P.-C.C.)

3 Department of Environmental Engineering, National I-Lan University, I-Lan 260, Taiwan; E-Mail: jlshie@niu.edu.tw

4 Institut für Funktionelle Grenzflächen, Karlsruher Institut für Technologie, Karlsruhe 76344, Germany; E-Mail: matthias.franzreb@kit.edu

5 Department of Energy Engineering, National United University, Miaoli 360, Taiwan; E-Mail: lychen888@gmail.com

* Author to whom correspondence should be addressed; E-Mail: yhchen1@ntut.edu.tw; Tel.: +886-2-27712171 (ext. 2539); Fax: +886-2-87724328.

Received: 29 June 2012; in revised form: 24 July 2012 / Accepted: 16 August 2012 / Published: 17 August 2012

\begin{abstract}
Blends of biodiesels produced from soapnut oil and high-oleic free fatty acids (FFAs), which are potential non-edible oil feedstocks, were investigated with respect to their fuel properties. The soapnut oil methyl esters (SNME) had satisfactory fuel properties with the exception of its high cold filter plugging point. In contrast, the biodiesel from the FFAs had favorable fuel properties such as a low cold filter plugging point of $-6{ }^{\circ} \mathrm{C}$; however, it exhibits poor oxidation stability with an induction period (IP) of $0.2 \mathrm{~h}$. The complementary blend of the SNME and the FFA-based biodiesel at various weight ratios was studied to improve the fuel properties. As a result, the biodiesel blend at a weight ratio of 70:30 can successfully meet all the biodiesel specifications, except the marginal oxidation stability. Furthermore, the effectiveness of $N, N$ '-di-sec-butyl- $p$ phenylenediamine at the concentration between 100 and $500 \mathrm{ppm}$ on the improvement in
\end{abstract}


the oxidation stability of the biodiesel blend was examined. The relationship between the IP values associated with the consumption of antioxidants in the biodiesel blends was described by first-order reaction rate kinetics. In addition, the natural logarithm of IP (ln IP) at various concentrations of antioxidant presented a linear relation with the test temperature. The IP at ambient temperature can be predicted based on the extrapolation of the temperature dependence relation.

Keywords: soapnut oil; free fatty acids; cold filter plugging point; oxidation stability; antioxidant; kinetics

\section{Introduction}

Recently, biodiesel has attracted a great deal of attention because of its nontoxic character and biodegradability [1]. Furthermore, biodiesel is considered carbon neutral and renewable. The utilization of biodiesel can contribute to the reduction of the carbon dioxide emissions. However, the use of edible oils for biodiesel production may be contrary to current social movements and energy policies. Non-edible vegetable oils, which are mostly produced by seed-bearing trees and shrubs, could be an alternative oil source.

Biodiesel generally has a higher cold filter plugging point (CFPP) and an inferior oxidation stability compared with petroleum diesel (a mixture of paraffinic, naphthenic, and aromatic hydrocarbons) [2]. The fuel can form solids of sufficient size to result in the filter plugging at the CFPP. Thus biodiesel with poor low-temperature flow properties could cause the clogging of the fuel lines and filters in the fuel system that limits the application of biodiesel in cold-weather climates [3]. In addition, the long term storage of biodiesel is related to its oxidation stability, which presently causes high concern of the major technical issues in the use of biodiesel. Oxidative stability is one of the major technical concerns with biodiesel [4].

Soapnut (Sapindus spp.) trees are generally found at altitudes ranging from 200 to $1500 \mathrm{~m}$ in tropical and sub-tropical climate areas including Asia, the Americas, and Europe [5]. Soapnut tree plantations have great potential to massively produce soapnut seeds and the oil content in the kernel of the soapnut seeds is approximately $42.7 \mathrm{wt} . \%$ [6,7]. The high content of monounsaturated fatty acids including oleic (9Z-octadecenoic, C18:1) and eicosenoic (11Z-eicosenoic, C20:1) acids in the soapnut oil is distinct compared with the fatty acid profiles of common vegetable oils [8]. According to the previous study [9], the soapnut oil methyl esters (SNME) exhibit superior oxidation stability. On the other hand, the CFPP of the SNME is $6{ }^{\circ} \mathrm{C}$, which exceeds the limits of the current biodiesel standards.

In addition to the transesterification of vegetable oils (triacylglycerols), biodiesel composed of fatty acid methyl esters is also obtained by the esterification of free fatty acids (FFAs) with low-molecular-weight alcohols. In some cases, FFAs are byproducts of the food-processing industry, such as the edible palm oil-based oleochemical industry, which releases $4 \%-8 \%$ of the total fatty acids as FFAs in crude palm oil during the physical refining process [10,11]. By converting the FFAs into biodiesel, a profitable system could be established to provide economic opportunities and benefit the environment without competing with the edible-oil market [12]. The FFA-based biodiesel has a low 
CFPP of $-6{ }^{\circ} \mathrm{C}$ and presents poor oxidation stability of an induction period (IP) of $0.2 \mathrm{~h}$ which can be attributed to the lack of natural antioxidants in the FFA-based biodiesel [13].

The auto-oxidation of fatty acid methyl esters (FAMEs) is a chain reaction involving three basic steps: initiation, propagation, and termination [14]. The time from the initial period to the stage with the maximum increase rate of conductivity has been defined as the IP. In general, the IP is experimentally determined by the Rancimat instrument based on EN 14,112, which is a standard method published by the European Committee in 2008 to evaluate the storage time of biodiesel. EN 14,214 standard requires that biodiesel must reach a minimum IP of $6 \mathrm{~h}$ at $110{ }^{\circ} \mathrm{C}$. ASTM D6751-07, a standard specification for biodiesel in America, includes an oxidation stability requirement of a minimum IP of 3 h. Furthermore, a modified European method EN 15,751 for biodiesel and diesel blends has been published in 2009 where a number of parameters, including a larger amount of fuel sample, an elongated reaction vessel, and a higher amount of distilled water, were changed compared with EN 14,112. The modifications are mainly due to higher volatility of diesel compared with biodiesel that may lead to higher sample evaporation [15]. To improve the oxidation stability of biodiesel, the addition of antioxidants is a promising approach to suppress auto-oxidation. If the antioxidant is active and its concentration is high enough, the transfer of hydrogen atom from the antioxidant to oxidative intermediates such as peroxyl radicals can break the chain propagation of the autoxidation process [16].

The first objective of this study was to study an optimum blending ratio of the SNME and high-oleic FFA-based biodiesel according to their complementary properties. Meanwhile, EN 14,214 and EN 15,751 tests were performed for comparison with respect of the measurement of oxidation stability at different test temperatures. As a result, the biodiesel blend can meet the biodiesel specifications except for the marginal oxidation stability. Thus $\mathrm{N}, \mathrm{N}^{\prime}$-di-sec-butyl-p-phenylenediamine (PDA), which is an aminic antioxidant, was used to improve the oxidation stability of the biodiesel blend. Furthermore, the consumption of the PDA in the biodiesel blend was described by first-order reaction rate kinetics. In addition, a linear relation between the natural logarithm of IP (ln IP) and the test temperature $\left(\mathrm{T},{ }^{\circ} \mathrm{C}\right)$ for the biodiesel blend stabilized with PDA was proposed. Based on the temperature dependence relation, the storage life of the biodiesel blend at an ambient temperature can be predicted by using an extrapolation method.

\section{Materials and Methods}

\subsection{Materials}

The soapnut oils were extracted from the seeds of soapnut trees (Sapindus mukorossi) planted in Fujian, China. The acid value of the soapnut oil was $13.4 \mathrm{mg} \mathrm{KOH} / \mathrm{g}$, indicating the need for acid-catalyzed esterification pretreatment. The high-oleic FFAs purchased from KLK Oleo Co., Ltd. (Rawang, Selangor Darul Ehsan, Malaysia) have the fatty acid composition shown in Table 1. The ACS-certified methanol was obtained from Mallinckrodt Chemicals (Phillipsburg, NJ, USA). The $\mathrm{H}_{2} \mathrm{SO}_{4}(96.7 \%$ purity) and $\mathrm{KOH}$ pellets (85\% purity) were purchased from Sigma-Aldrich (St. Louis, MO, USA) and Riedel-deHaën (St. Gallen, Switzerland), respectively. Anhydrous magnesium sulfate 
was obtained from Showa (Tokyo, Japan). The PDA with a purity of $98 \%$ was purchase from TCI (Tokyo, Japan).

Table 1. Fatty acid composition of high-oleic FFAs as well as SNME and FFA-based biodiesel blend ${ }^{\text {a }}$.

\begin{tabular}{lcc}
\hline \multicolumn{1}{c}{ Fatty acid } & High-oleic FFAs [13] & SNME and FFA-based biodiesel blend \\
\hline Palmitic acid (C16:0) & 1.39 & 3.0 \\
Stearic acid (C18:0) & 4.30 & 2.6 \\
Oleic acid (C18:1) & 81.7 & 65.2 \\
Linoleic acid (C18:2) & 11.2 & 9.4 \\
Linolenic acid (C18:3) & 0.19 & 1.6 \\
Arachidic acid (C20:0) & 0.8 & 3.5 \\
Eicosenoic acid (C20:1) & 0.3 & 14.5 \\
Lignoceric acid (C24:0) & 0.1 & 0.0 \\
Saturated fatty acids & 6.59 & 9.1 \\
Unsaturated fatty acids & 93.39 & 90.7 \\
\hline
\end{tabular}

${ }^{\mathrm{a}}$ Values are in the unit of wt.\%.

\subsection{Experimental Procedures}

For the esterification pretreatment of the soapnut oil, $439 \mathrm{~g}$ methanol and $11 \mathrm{~g} \mathrm{H}_{2} \mathrm{SO}_{4}$ was added to $2751 \mathrm{~g}$ soapnut oil under vigorous mixing at $60{ }^{\circ} \mathrm{C}$ for reaction time of $1 \mathrm{~h}$ to obtain an acid value of $0.01 \mathrm{mg} \mathrm{KOH} / \mathrm{g}$. Then the methanolysis of the esterified soapnut oil was performed for another $1 \mathrm{~h}$ in the experimental conditions including a molar ratio of methanol to soapnut oil of $6: 1$, reaction temperature of $60^{\circ} \mathrm{C}$, and $\mathrm{KOH}$ catalyst dosage based on the oil weight of $1 \% \mathrm{w} / \mathrm{w}$. $\mathrm{KOH}$ was chosen as the catalyst because of its low cost though alkoxides such as sodium methoxide may be work better for base-catalyzed transesterification. Subsequently, the ester phase was washed twice with a saturated sodium chloride solution (three times the volume of the ester phase) to remove any residual methanol, $\mathrm{KOH}$, or glycerol that may have been present. Finally, the trace amounts of water in the biodiesels were removed by adding anhydrous magnesium sulfate, followed by filtration [17].

The FFA-based biodiesel was prepared by the esterification reaction of the FFAs in the experimental conditions including a molar ratio of methanol to FFAs of 12:1, a reaction temperature of $55{ }^{\circ} \mathrm{C}, \mathrm{a} \mathrm{H}_{2} \mathrm{SO}_{4}$ catalyst dosage of $5 \% \mathrm{w} / \mathrm{w}$ based on the FFAs weight, and a reaction time of $2 \mathrm{~h}$. Then the ester phase was neutralized with $\mathrm{KOH}$ solution and washed twice with a saturated sodium chloride solution, followed by the drying.

\subsection{Analysis of Fuel Properties}

Acid value, cetane number, CFPP, density, flash point, iodine value, and kinematic viscosity were determined according to EN 14,104, ASTM D613, EN 116, EN ISO 3675, ASTM D93, EN 14,111, and EN ISO 3104, respectively. In addition, the ester content and FAME composition were analyzed according to EN 14,103. The IPs of the biodiesel were determined by using the Rancimat equipment model 873 (Metrohm, Herisau, Switzerland). The IP was determined by the measurement of a rapid increase in the conductivity upon the formation of volatile acids [18]. All determinations of the IP were 
performed in duplicate and the mean values were reported to two decimal places. In addition, the effectiveness of the antioxidant on the oxidation stability of the FFA-based biodiesel is expressed by the stabilization factor $[4,18,19-21]$ :

$$
\text { Stabilization factor }=\mathrm{IP} / \mathrm{IP}_{\mathrm{ORIG}}
$$

where $\mathrm{IP}_{\mathrm{ORIG}}$ means the IP for biodiesel without the addition of any antioxidant.

\subsection{Reaction Rate Kinetics for Consumption of Antioxidant}

The consumption rate of the antioxidant can be described by the first-order reaction rate kinetics as:

$$
\frac{\mathrm{dC}}{\mathrm{dt}}=-\mathrm{k}_{\mathrm{f}} \mathrm{C}
$$

where $\mathrm{k}_{\mathrm{f}}$ is the reaction rate constant of the antioxidant consumption. The concentration of the antioxidant $(\mathrm{C})$ decreases with the oxidation time ( $\mathrm{t}$ ) and becomes $\mathrm{C}_{\mathrm{cr}}$ at $\mathrm{t}=\mathrm{IP}-\mathrm{IP}_{\text {ORIG }}$ [22]. The $\mathrm{C}_{\mathrm{cr}}$ refers to the critical concentration of the antioxidant below which the antioxidant has no noticeable effect on retarding the oxidation of biodiesel. Integration of Equation (1) within the concentration range from the initial concentration of the antioxidant $\left(\mathrm{C}_{0}\right)$ to $\mathrm{Ccr}$ and the time limits from $\mathrm{t}=0$ to $\mathrm{t}=\mathrm{IP}-\mathrm{IPORIG}$ reveals how $\mathrm{C}$ varies with $\mathrm{t}$, as shown in Equation (2):

$$
-\int_{\mathrm{C}_{0}}^{\mathrm{C}_{\mathrm{cr}}} \frac{\mathrm{dC}}{\mathrm{C}}=\int_{0}^{{ }^{\mathrm{IP}-\mathrm{IP}} \mathrm{PRIG}} \mathrm{k}_{\mathrm{f}} \mathrm{dt}
$$

As a result, a linear relation between the $\ln \mathrm{C}_{0}$ and IP - IP $\mathrm{PRIG}_{\text {can }}$ be obtained as shown in Equation (3):

$$
\ln \mathrm{C}_{0}=\mathrm{k}_{\mathrm{f}}\left(\mathrm{IP}-\mathrm{IP}_{\mathrm{ORIG}}\right)+\ln \mathrm{C}_{\mathrm{cr}}
$$

The slope and intercept of the straight line represent the values of $\mathrm{k}_{\mathrm{f}}$ and $\ln \mathrm{C}_{\mathrm{cr}}$, respectively. The low value of $\mathrm{k}_{\mathrm{f}}$ represented the superior performance of the antioxidant for oxidation stability, while the $\mathrm{C}_{\mathrm{cr}}$ presented a threshold dose required to show a significant increase in the IP.

\section{Results and Discussion}

\subsection{Properties of SNME and FFA-based Biodiesel Blends}

The variations of CFPP and IP with the weight percentage of the FFA-based biodiesel (wt.\%) for the SNME and FFA-based biodiesel blends are shown in Figure 1. The CFPP of the blend continuously decreased with the increase of the weight percentage of the FFA-based biodiesel. When the FFA-based biodiesel increased to $30 \mathrm{wt} . \%$, the CFPP of the biodiesel blends decreased to $0{ }^{\circ} \mathrm{C}$ which satisfied the requirement of Grade A to B in EN 14,214 in Europe or CNS 15,072 in Taiwan. However, the IP of the biodiesel blend would significantly decrease with the increasing weight percentage of the FFA-based biodiesel. When the weight percentage of the FFA-based biodiesel was $30 \mathrm{wt} . \%$ or higher, the IP of the blend was below the lower value of $6 \mathrm{~h}$ at $110^{\circ} \mathrm{C}$ as specified in EN 14,214 and CNS 15,072. One may address that the oxidation stability of the biodiesel blend was still greater than $3 \mathrm{~h}$ as specified in ASTM D6751 until the FFA-based biodiesel reached to $60 \mathrm{wt} \%$ in 
the blends. Obviously, the SNME and FFA-based biodiesel blends showed the complementary characteristics in respect of CFPP and oxidation stability.

Figure 1. The variations of CFPP and IP with the weight percentage of FFA-based biodiesel (wt.\%) for SNME and FFA-based biodiesel blends. $\circ$ and $\Delta$ : CFPP and IP, respectively.

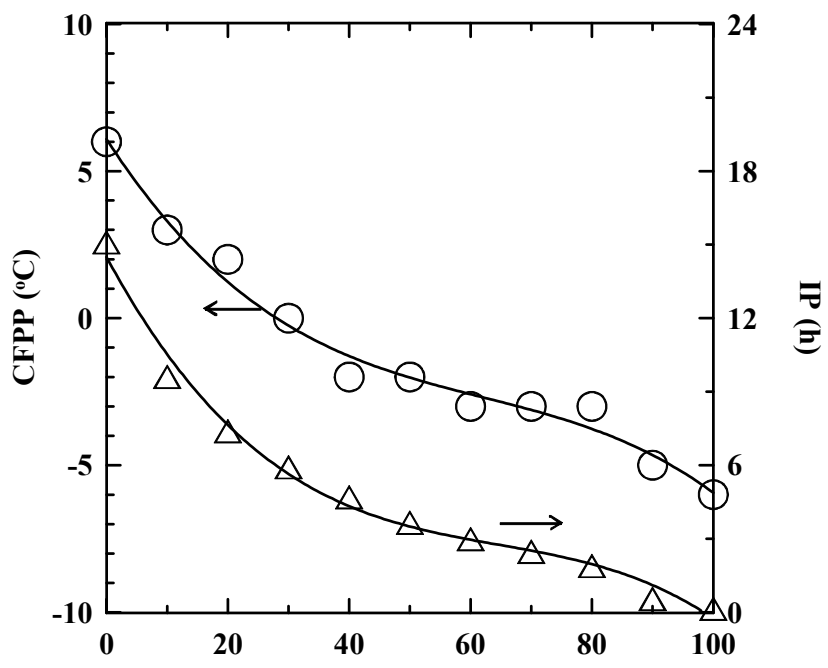

Weight percentage ratio of FFA-based biodiesel (wt.\%)

According to the property variations, the blending ratio of SNME and FFA-based biodiesel at 70:30 wt.\% gave a CFPP of $0{ }^{\circ} \mathrm{C}$ and oxidation stability of $5.9 \mathrm{~h}$. The biodiesel blend can satisfy the specifications except for marginal oxidation stability as specified in EN 14,214 and CNS 15,072. Therefore, this study further examined the addition of PDA for the improvement of the oxidation stability of the biodiesel blend. The SNME and FFA-based biodiesel blend at 60:40 wt.\% was chosen as the model case for the following investigation and had the fatty acid composition as shown in Table 1. The properties of the biodiesel blend are given in Table 2 and further compared with various biodiesel specifications including ASTM D6751 in the United States, CNS 15,072 in Taiwan, and EN 14,214 in Europe.

Table 2. Properties of SNME and FFA-based biodiesel blend compared with ASTM D6751, CNS 15,072, and EN 14,214 specifications.

\begin{tabular}{llcccc}
\hline \multicolumn{1}{c}{ Property } & \multicolumn{1}{c}{ Unit } & SNME and FFA-based biodiesel blend & ASTM D6751 & CNS 15072 & EN 14214 \\
\hline Acid value & $\mathrm{mg} \mathrm{KOH} / \mathrm{g}$ & 0.18 & $0.5 \max$ & $0.5 \mathrm{max}$ & $0.5 \mathrm{max}$ \\
Cetane number & - & 58 & $47 \mathrm{~min}$ & $51 \mathrm{~min}$ & $51 \mathrm{~min}$ \\
$\mathrm{CFPP}$ & ${ }^{\circ} \mathrm{C}$ & -2 & $\mathrm{a}$ & $0 \mathrm{max}$ & $860-900$ \\
Density at $15{ }^{\circ} \mathrm{C}$ & $\mathrm{kg} / \mathrm{m}^{3}$ & 878 & $\mathrm{~b}$ & $860-900$ \\
Ester content & $\%(\mathrm{~m} / \mathrm{m})$ & 98.6 & $\mathrm{~b}$ & $96.5 \mathrm{~min}$ & $96.5 \mathrm{~min}$ \\
Flash point & ${ }^{\circ} \mathrm{C}$ & 169 & $\mathrm{~b}$ & $120 \mathrm{max}$ & $120 \mathrm{max}$ \\
Iodine value & $\mathrm{g} \mathrm{I}_{2} / 100 \mathrm{~g}$ & 95.7 & $1.9-6.0$ & $3.50-5.0$ & $3.50-5.0$ \\
Kinematic viscosity at $40^{\circ} \mathrm{C}$ & $\mathrm{mm}^{2} / \mathrm{s}$ & 4.82 & $3.0 \mathrm{~min}$ & $6 \mathrm{~min}$ \\
Oxidation stability, $110^{\circ} \mathrm{C}$ & $\mathrm{h}$ & 4.7 & $6 \mathrm{~min}$ \\
\hline
\end{tabular}

${ }^{a}$ Not specified; depends upon the location and time of year; ${ }^{b}$ Not specified. 


\subsection{Temperature Dependence of IP and Enhanced with Addition of PDA}

The IP of the biodiesel blend was clearly a function of the T and the PDA concentration $\left(\mathrm{C}_{0}\right)$ over the experimental range, as illustrated in Figure 2. Apparently, a lower $\mathrm{T}$ or a higher $\mathrm{C}_{0}$ clearly caused a longer IP. In addition, the IP determined by EN 15,751 was slightly higher than that determined by EN 14,112 that may be caused from slower consumption of PDA by EN 15,751. At the $\mathrm{C}_{0}$ of $50 \mathrm{ppm}$, it showed negligible enhancement on the IP for all T. Furthermore, the IP started to remarkably increase with higher $\mathrm{C}_{0}$ where it appeared to be nonlinear curves, which was also observed in the previous studies $[4,18,20,21,23]$. Furthermore, the effectiveness of PDA at $500 \mathrm{ppm}$ on the IP was evaluated by the stabilization factor (Table 3). The PDA presented the similar effectiveness at different $\mathrm{T}$ with an average stabilization factor of about 3.78 although the IPORIG of the biodiesel blend was remarkably great at a low T. As a result, the addition of PDA at $100 \mathrm{ppm}$ was able to prolong the IP of the biodiesel blend greater than $6 \mathrm{~h}$ at $110^{\circ} \mathrm{C}$ to satisfy the requirement of oxidation stability.

Figure 2. The variations of IP with $\mathrm{C}_{0}$ for the SNME and FFA-based biodiesel blend at $90{ }^{\circ} \mathrm{C}, 100{ }^{\circ} \mathrm{C}, 110{ }^{\circ} \mathrm{C}$, and $120{ }^{\circ} \mathrm{C}$, as determined by Rancimat method with the addition of PDA. Symbol, line: experimental data, prediction. $\bigcirc$ and $\Delta$ : EN 14,112 and EN 15,751, respectively.

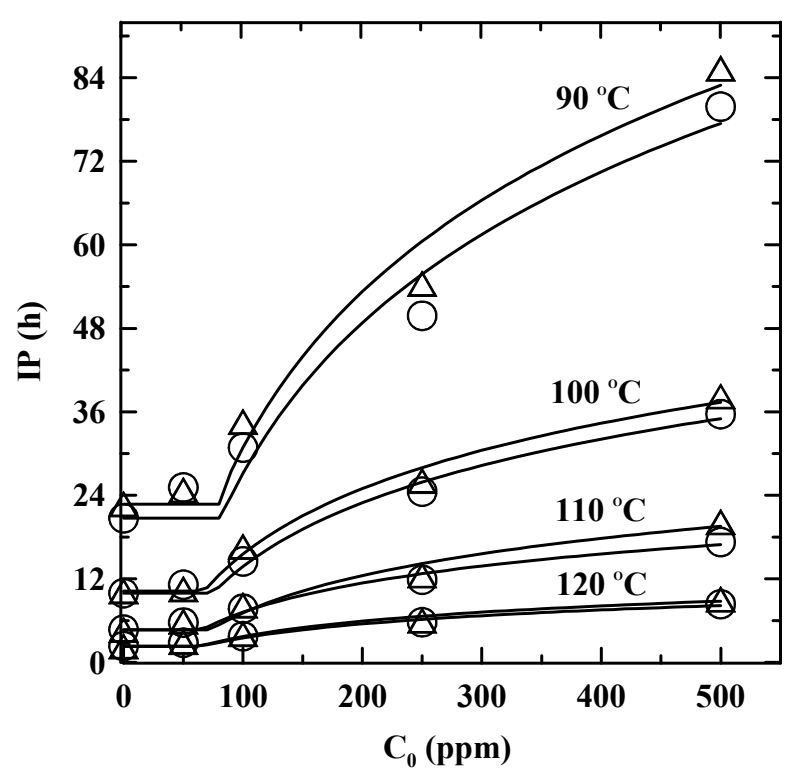

Table 3. The $\mathrm{IP}_{\mathrm{ORIG}}$ and stabilization factor, $\mathrm{k}_{\mathrm{f}}$, and $\mathrm{C}_{\mathrm{Cr}}$ for consumption of PDA in the biodiesel blend at various temperature according to EN1411 and EN15,751.

\begin{tabular}{ccccccc}
\hline $\mathbf{T}\left({ }^{\circ} \mathbf{C}\right)$ & Method & $\mathbf{I P}_{\text {ORIG }}(\mathbf{h})$ & Stabilization factor $^{\mathbf{a}}$ & $\mathbf{k}_{\mathbf{f}}\left(\mathbf{h}^{\mathbf{- 1}}\right)$ & $\mathbf{C}_{\mathbf{c r}}(\mathbf{p p m})$ & $\mathbf{R}^{\mathbf{2}}$ \\
\hline \multirow{2}{*}{90} & EN 14,112 & 20.70 & 3.86 & 0.0320 & 81.4 & 0.977 \\
& EN 15,751 & 22.74 & 3.75 & 0.0309 & 77.8 & 0.958 \\
\multirow{2}{*}{100} & EN 14,112 & 9.94 & 3.59 & 0.0827 & 63.8 & 0.976 \\
& EN 15,751 & 10.25 & 3.73 & 0.0768 & 62.6 & 0.944 \\
\multirow{2}{*}{110} & EN 14,112 & 4.70 & 3.60 & 0.166 & 66.9 & 0.970 \\
& EN 15,751 & 4.70 & 4.20 & 0.126 & 74.1 & 0.967 \\
\multirow{2}{*}{120} & EN 14,112 & 2.33 & 3.58 & 0.346 & 66.3 & 0.977 \\
& EN 15,751 & 2.30 & 3.93 & 0.316 & 63.8 & 0.958 \\
\hline
\end{tabular}

${ }^{\text {a }}$ Determined with the $\mathrm{C}_{0}$ at $500 \mathrm{ppm}$. 


\subsection{Reaction Rate Kinetics for Consumption of PDA}

The experimental data in Figure 2 was further employed to study the reaction rate kinetics for the consumption of PDA in the biodiesel blend. As shown in Table 1, the values of $\mathrm{k}_{\mathrm{f}}$ and $\mathrm{C}_{\mathrm{cr}}$ were determined by the slope and intercept of the straight line based on Equation (3), respectively, with high coefficient of determination $\left(\mathrm{R}^{2}\right)$. The prediction of the IP based on the obtained reaction rate kinetics showed the satisfactory agreement with the experimental data, as illustrated in Figure 2. It was obvious that the kf significantly increased as $\mathrm{T}$ increased while the $\mathrm{C}_{\mathrm{cr}}$ comparatively remained constant with an average value of $70 \mathrm{ppm}$ at different $\mathrm{T}$. Moreover, the $\mathrm{k}_{\mathrm{f}}$ and $\mathrm{C}_{\mathrm{cr}}$ at $110{ }^{\circ} \mathrm{C}$ were determined as $0.166 \mathrm{~h}^{-1}$ and $66.9 \mathrm{ppm}$, respectively, based on EN 14,112. In contrast, the $\mathrm{kf}$ and $\mathrm{C}_{\mathrm{cr}}$ values based on EN 15,751 were found lower $\left(0.126 \mathrm{~h}^{-1}\right)$ and similar $(74.1 \mathrm{ppm})$, respectively, that evidenced slower consumption rate of PDA.

Figure 3 shows $\ln \mathrm{k}_{\mathrm{f}} v s . \mathrm{T}^{-1}$ based on the Arrhenius equation, $\mathrm{k}_{\mathrm{f}}=\mathrm{A} \exp ^{-\mathrm{Ea} /(\mathrm{RT})}$, where $\mathrm{A}, \mathrm{Ea}$, and $\mathrm{R}$ are the pre-exponential factor, the activation energy, and the ideal gas law constant of $8.314 \mathrm{~J} /(\mathrm{mol} \cdot \mathrm{K})$, respectively. The values of $\mathrm{A}$ and Ea for the consumption of PDA were determined as $8.29 \times 10^{11} \mathrm{~h}^{-1}$ and $93.07 \mathrm{~kJ} / \mathrm{mol}$, respectively, for EN 14,112. On the other hand, A and Ea were $1.97 \times 10^{11} \mathrm{~h}^{-1}$ and $88.90 \mathrm{~kJ} / \mathrm{mol}$, respectively, for EN 15,751. Note that the higher A value for EN 14,112, indicating higher frequency of molecules collision of PDA and oxygen, mainly responded to higher consumption rate of PDA. In addition, the Ea value was between those obtained for the consumption of Ethanox $4760 \mathrm{E}(85.68 \mathrm{~kJ} / \mathrm{mol})$ and propyl gallate $(97.02 \mathrm{~kJ} / \mathrm{mol})$ [22], indicating the similar mechanism of the antioxidant consumption.

Figure 3. Temperature dependence of the $\ln \mathrm{k}_{\mathrm{f}}$ for the consumption of PDA in the SNME

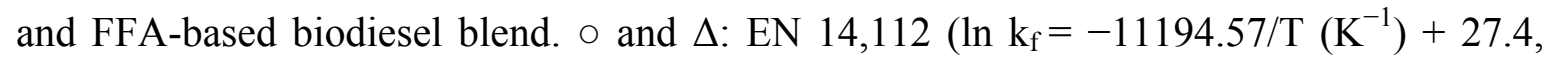
$\left.\mathrm{R}^{2}=0.997\right)$ and $\mathrm{EN} 15,751\left(\ln \mathrm{k}_{\mathrm{f}}=-10693.11 / \mathrm{T}\left(\mathrm{K}^{-1}\right)+26.0, \mathrm{R}^{2}=0.990\right)$, respectively.

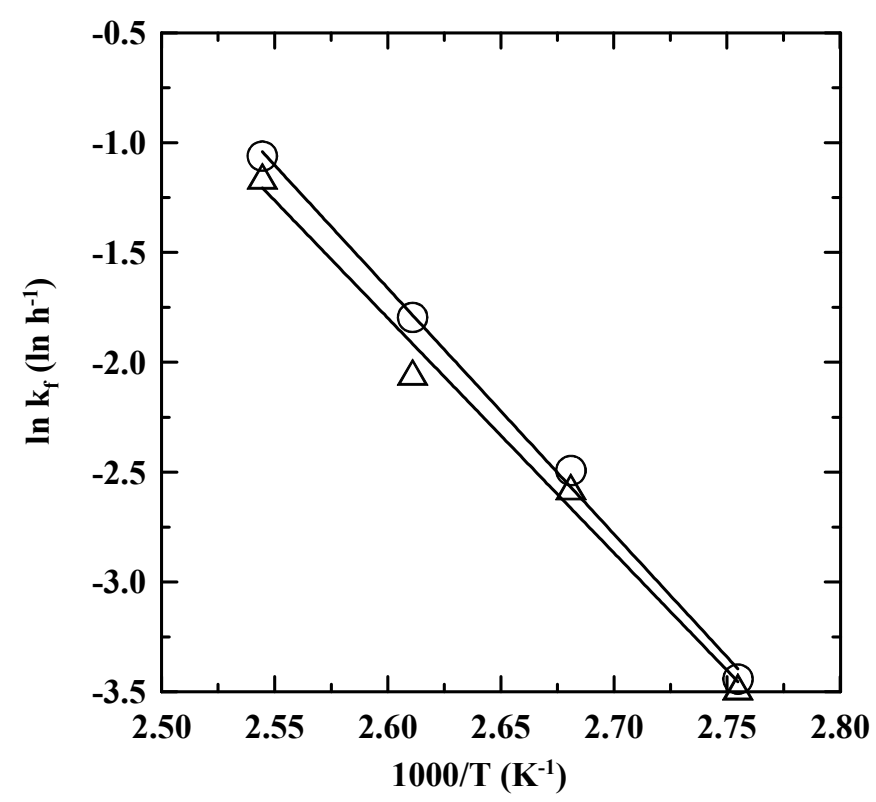




\subsection{IP at Ambient Temperature as Obtained by an Extrapolation Method}

Figure 4a illustrates a linear relationship between the $\ln$ IP and $\mathrm{T}$ for the biodiesel blend with $\mathrm{C}_{0}$ at $0,100,250,500 \mathrm{ppm}$. It was consistent with the findings of Xin et al. [22] who presented a linear relation between the In IP and T of safflower biodiesel stabilized with propyl gallate. On the other hand, the linear relationship between the $\ln \mathrm{IP}$ and $1 / \mathrm{T}\left(\mathrm{K}^{-1}\right)$ was proposed according to Equation (3) and the Arrhenius equation which has been shown in Figure $4 \mathrm{~b}$. The temperature-dependent correlations of $\ln$ IP for the SNME and FFA-based biodiesel blend stabilized with various $\mathrm{C}_{0}$ of PDA using EN 14,112 and EN 15,751 are highly linear as shown in Table 4. Then the storage time of biodiesel at ambient temperatures could be predicted by extrapolating the temperature-dependent correlations.

Figure 4. The relationship between $\ln$ IP and $\mathrm{T}$ for the SNME and FFA-based biodiesel blend stabilized with various $\mathrm{C}_{0}$ of PDA. $\circ$ and $\Delta$ : EN 14,112 and EN 15,751, respectively. (a) Linear relationship between $\ln$ IP and $\mathrm{T}\left({ }^{\circ} \mathrm{C}\right)$; (b) linear relationship between $\ln$ IP and $1 / \mathrm{T}\left(\mathrm{K}^{-1}\right)$.

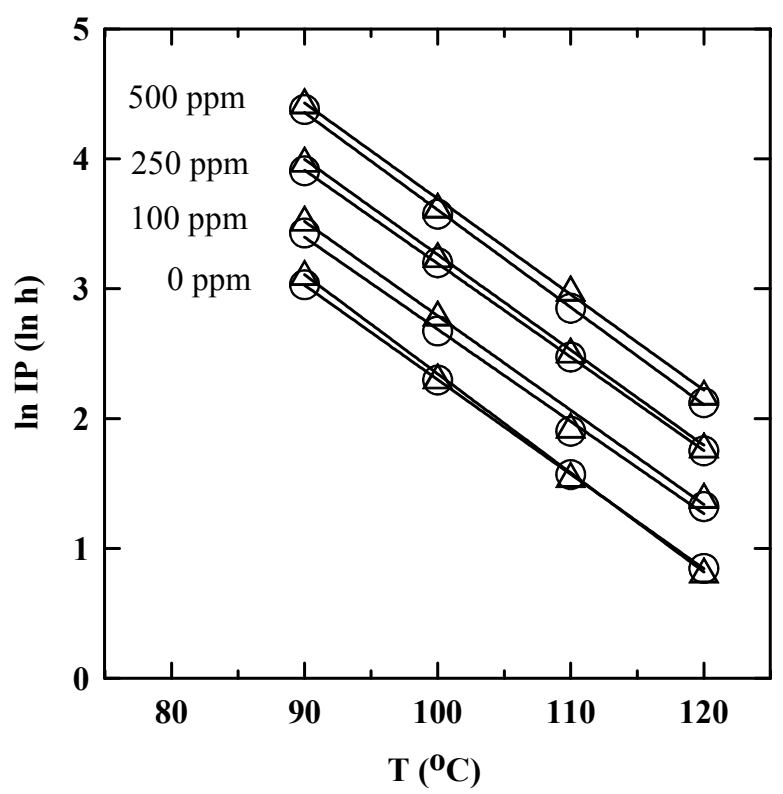

(a)

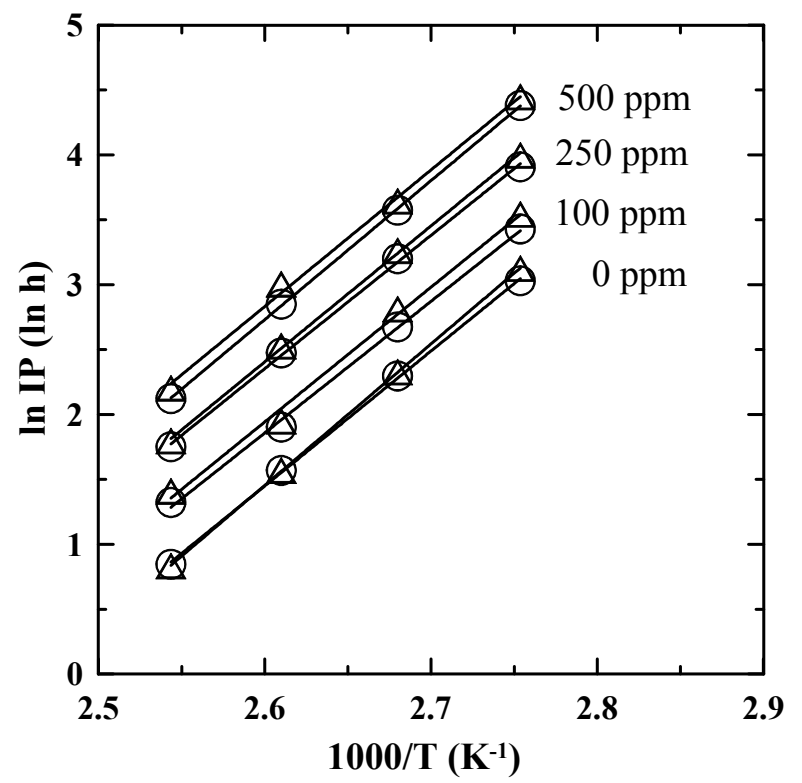

(b)

Table 4. The temperature-dependent correlations of In IP for the SNME and FFA-based biodiesel blend stabilized with various $\mathrm{C}_{0}$ of PDA using EN 14,112 and EN 15,751.

\begin{tabular}{cll}
\hline C0 (ppm) & \multicolumn{1}{c}{ EN 14,112 } & \multicolumn{1}{c}{ EN 15,751 } \\
\hline \multirow{2}{*}{0} & $\ln \mathrm{IP}=-0.0728 \mathrm{~T}+9.58, \mathrm{R}^{2}=0.999$ & $\ln \mathrm{IP}=-0.0763 \mathrm{~T}+9.98, \mathrm{R}^{2}=1$ \\
& $\ln \mathrm{IP}=10391.35 / \mathrm{T}-25.568, \mathrm{R}^{2}=0.999$ & $\ln \mathrm{IP}=10896.89 / \mathrm{T}-26.9, \mathrm{R}^{2}=1$ \\
\multirow{2}{*}{100} & $\ln \mathrm{IP}=-0.0708 \mathrm{~T}+9.84, \mathrm{R}^{2}=0.999$ & $\ln \mathrm{IP}=-0.0717 \mathrm{~T}+10.0, \mathrm{R}^{2}=0.999$ \\
& $\ln \mathrm{IP}=10139 / \mathrm{T}-24.5, \mathrm{R}^{2}=0.998$ & $\ln \mathrm{IP}=10381 / \mathrm{T}-25.1, \mathrm{R}^{2}=0.995$ \\
\multirow{2}{*}{250} & $\ln \mathrm{IP}=-0.072 \mathrm{~T}+10.4, \mathrm{R}^{2}=1$ & $\ln \mathrm{IP}=-0.0734 \mathrm{~T}+10.6, \mathrm{R}^{2}=1$ \\
& $\ln \mathrm{IP}=10270 / \mathrm{T}-24.3, \mathrm{R}^{2}=0.999$ & $\ln \mathrm{IP}=10477 / \mathrm{T}-24.8, \mathrm{R}^{2}=0.999$ \\
\multirow{2}{*}{500} & $\ln \mathrm{IP}=-0.075 \mathrm{~T}+11.1, \mathrm{R}^{2}=0.999$ & $\ln \mathrm{IP}=-0.0737 \mathrm{~T}+11.1, \mathrm{R}^{2}=0.998$ \\
& $\ln \mathrm{IP}=10706 / \mathrm{T}-25.1, \mathrm{R}^{2}=0.999$ & $\ln \mathrm{IP}=10520 / \mathrm{T}-24.5, \mathrm{R}^{2}=0.998$ \\
\hline
\end{tabular}


Figure 5 compared the differences of the predicted IP at $25{ }^{\circ} \mathrm{C}$ with $\mathrm{C}_{0}$. Apparently, the storage time predicted based on the reaction rate kinetics was about 4.51-4.96 times longer than that predicted by the linear relationship between In IP and T. Furthermore, the predicted IP based on EN 15,751 was slightly higher than that based on EN 14,112 especially for the region of low $\mathrm{C}_{0}$. According to the prediction of reaction rate kinetics, the biodiesel blend can be stored more 449 days. However, approximately $200 \mathrm{ppm}$ and $150 \mathrm{ppm}$ of PDA was required to guarantee a half year of storage, which is the current recommendation for biodiesel shelf life [24,25], based on EN 14,112 and EN 15,751, respectively. It was obvious that the further study is required to verify the validity of the two prediction models for biodiesel shelf life.

Figure 5. The predicted IP of the SNME and FFA-based biodiesel blend at $25{ }^{\circ} \mathrm{C}$ with $\mathrm{C}_{0}$. - and -----: EN 14,112 and EN 15,751, respectively, as predicted by the linear relationship between $\ln$ IP and T. - - - and - - : EN 14,112 and EN 15,751, respectively, as predicted by the reaction rate kinetics.

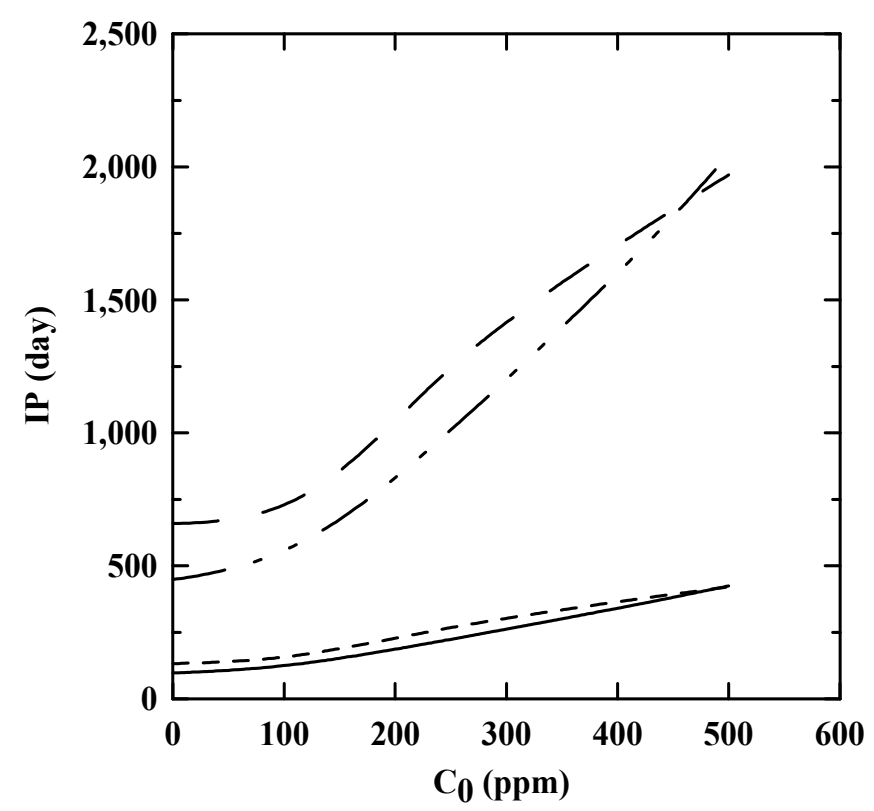

\section{Conclusions}

The soapnut oil methyl esters (SNME) and high-oleic free fatty acids (FFA)-based biodiesel showed complementary properties. The SNME and FFA-based biodiesel at 70:30 wt.\% can satisfy the biodiesel specifications, except the marginal oxidation stability. The addition of $\mathrm{N}, \mathrm{N}^{\prime}$-di-sec-butyl-p-phenylenediamine (PDA) at $100 \mathrm{ppm}$ was recommended for the improvement of the oxidation stability. In addition, the consumption rate of the PDA in the biodiesel blend can be described by the first-order reaction rate kinetics. The biodiesel shelf life predicted by the reaction rate kinetics is significantly higher than that by the linear relationship between the natural logarithm of induction period and temperature.

\section{Acknowledgement}

This study was supported by the National Science Council of Taiwan. 


\section{References}

1. Meher, L.C.; Sagar, D.V.; Naik, S.N. Technical aspects of biodiesel production by transesterification-A review. Renew. Sustain. Energy Rev. 2006, 10, 248-268.

2. Moser, B.R.; Knothe, G.; Cermak, S.C. Biodiesel from meadowfoam (Limnanthes alba L.) seed oil: Oxidative stability and unusual fatty acid composition. Energy Environ. Sci. 2010, 3, 318-327.

3. Park, J.Y.; Kim, D.K.; Lee, J.P.; Park. S.C.; Kim, Y.J.; Lee, J.S. Blending effects of biodiesels on oxidation stability and low temperature flow properties. Bioresour. Technol. 2008, 99, 1196-1203.

4. Schober, S.; Mittellbach, M. The impact of antioxidants on biodiesel oxidation stability. Eur. J. Lipid Sci. Technol. 2004, 106, 382-389.

5. Haryana-online.com. Ritha. 2007. Available online: http://www.haryana-online.com/Flora/ritha.htm (accessed on 17 August 2012)

6. Chhetri, A.B.; Tango, M.S.; Budge, S.M.; Watts, K.C.; Islam, M.R. Non-edible plant oils as new sources for biodiesel production. Int. J. Mol. Sci. 2008, 9, 169-180.

7. Huang, S.; Wang, J.; Du, M.; Zhang, J.; Jiang, J. Fatty acid composition analysis of Sapindus mukorossi Gaerth seed oil (in Chinese). China Oils Fats 2009, 34, 74-76.

8. Misra, R.D.; Murthy, M.S. Performance, emission and combustion evaluation of soapnut oil-diesel blends in a compression ignition engine. Fuel 2011, 90, 2514-2518.

9. Chen, Y.H.; Chiang, T.H.; Chen, J.H. An optimum biodiesel combination: Jatropha and soapnut oil biodiesel blends. Fuel 2011, 92, 377-380.

10. Ng, W.K.; Lim, P.K.; Boey, P.L. Dietary lipid and palm oil source affects growth, fatty acid composition and muscle $\alpha$-tocopherol concentration of African catfish, Clarias gariepinus. Aquaculture 2003, 215, 229-243.

11. Aranda, D.A.G.; Santos, R.T.P.; Tapanes, N.C.O.; Ramos, A.L.D.; Antunes, O.A.C. Acid-catalyzed homogeneous esterification reaction for biodiesel production from palm fatty acids. Catal. Lett. 2008, 122, 20-25.

12. Ooi, Y.S.; Zakaria, R.; Mohamed, A.R.; Bhatia, S. Catalytic conversion of palm oil-based fatty acid mixture to liquid fuel. Biomass Bioenergy 2004, 27, 477-484.

13. Chen, Y.H.; Luo, Y.M. Oxidation stability of biodiesel derived from free fatty acids associated with kinetics of antioxidants. Fuel Process. Technol. 2011, 92, 1387-1393.

14. Waynick, J.A. Characterization of Biodiesel Oxidation and Oxidation Products; National Renewable Energy Laboratory: Lakewood, CO, USA, 2005; pp. 3-5.

15. Karavalakis, G.; Stournas, S.; Karonis, D. Evaluation of the oxidation stability of diesel/biodiesel blends. Fuel 2010, 89, 2483-2489.

16. Dunn, R.O. Effect of antioxidants on the oxidation stability of methyl soyate (biodiesel). Fuel Process. Technol. 2005, 86, 1071-1085.

17. Moser, B.R. Influence of blending canola, palm, soybean, and sunflower oil methyl esters on fuel properties of biodiesel. Energy Fuels 2008, 22, 4301-4306.

18. Araújo, S.V.; Luna, F.M.T.; Rola, E.M., Jr.; Azevedo, D.C.S.; Cavalcante, C.L., Jr. A rapid method for evaluation of the oxidation stability of castor oil FAME: Influence of antioxidant type and concentration. Fuel Process. Technol. 2009, 90, 1272-1277. 
19. Denisov, E.T.; Khudyakov, I.V. Mechanisms of action and reactivities of the free radicals of inhibitors. Chem. Rev. 1987, 87, 1313-1357.

20. Domingos, A.K.; Saad. E.B.; Vechiatto, W.W.D.; Wilhelm, H.M.; Ramos, L.P. The influence of BHA, BHT and TBHQ on the oxidation stability of soybean oil ethyl esters (biodiesel). J. Braz. Chem. Soc. 2007, 18, 416-423.

21. Guzman, R.D.; Tang, H.; Salley, S.; Ng, K.Y.S. Synergistic effects of antioxidants on the oxidation stability of soybean oil- and poultry fat-based biodiesel. J. Am. Oil Chem. Soc. 2009, 86, 459-467.

22. Xin, J.; Imahara, H.; Saka, S. Kinetics on the oxidation of biodiesel stabilized with antioxidant. Fuel 2009, 88, 282-286.

23. Chen, Y.H.; Chen, J.H.; Luo, Y.M.; Shang, N.C.; Chang, C.H.; Chang, C.Y.; Chiang, P.C.; Shie J.L. Property modification of jatropha oil biodiesel by blending with other biodiesels or adding antioxidants. Energy 2011, 36, 4415-4421.

24. Tang, H.; Guzman, R.D.; Salley, S.O.; Ng, K.Y.S. The oxidation stability of biodiesel: Effects of FAME composition and antioxidant. Lipid Technol. 2008, 20, 249-252.

25. Bondioli, P.; Gasparoli, A.; Bella, L.; Tagliabue, S.; Toso, G. Biodiesel stability under commercial storage conditions over one year. Eur. J. Lipid Sci. Technol. 2003, 105, 735-741.

(C) 2012 by the authors; licensee MDPI, Basel, Switzerland. This article is an open access article distributed under the terms and conditions of the Creative Commons Attribution license (http://creativecommons.org/licenses/by/3.0/). 